\title{
Systematic study on the relationship between particulate matter and microbial counts in hospital operating rooms
}

\author{
Huiyi Tan ${ }^{1} \cdot$ Keng Yinn Wong ${ }^{2,3}$ (D) Bemgba Bevan Nyakuma ${ }^{4} \cdot$ Haslinda Mohamed Kamar $^{2} \cdot$ Wen Tong Chong ${ }^{5}$. \\ Syie Luing Wong ${ }^{6} \cdot$ Hooi Siang Kang ${ }^{2}$
}

Received: 11 June 2021 / Accepted: 22 August 2021 / Published online: 30 August 2021

(C) The Author(s), under exclusive licence to Springer-Verlag GmbH Germany, part of Springer Nature 2021

\begin{abstract}
In this study, a systematic procedure for establishing the relationship between particulate matter (PM) and microbial counts in four operating rooms (ORs) was developed. The ORs are located in a private hospital on the western coast of Peninsular Malaysia. The objective of developing the systematic procedure is to ensure that the correlation between the PMs and microbial counts are valid. Each of the procedures is conducted based on the ISO, IEST, and NEBB standards. The procedures involved verifying the operating parameters are air change rate, room differential pressure, relative humidity, and air temperature. Upon verifying that the OR parameters are in the recommended operating range, the measurements of the PMs and sampling of the microbes were conducted. The TSI 9510-02 particle counter was used to measure three different sizes of PMs: PM 0.5, PM 5, and PM 10. The MAS-100ECO air sampler was used to quantify the microbial counts. The present study confirms that PM 0.5 does not have an apparent positive correlation with the microbial count. However, the evident correlation of $7 \%$ and $15 \%$ were identified for both PM 5 and PM 10, respectively. Therefore, it is suggested that frequent monitoring of both PM 5 and PM 10 should be practised in an OR before each surgical procedure. This correlation approach could provide an instantaneous estimation of the microbial counts present in the OR.
\end{abstract}

Keywords Operating room $\cdot$ Particulate matter $\cdot$ Microbial count $\cdot$ Air change rate $\cdot$ Differential pressure $\cdot$ Onsite sampling

Responsible Editor: Lotfi Aleya

Keng Yinn Wong

kengyinnwong@utm.my

1 School of Chemical and Energy Engineering, Faculty of Engineering, Universiti Teknologi Malaysia, 81310 Skudai, Johor, Malaysia

2 School of Mechanical Engineering, Faculty of Engineering, Universiti Teknologi Malaysia, 81310 Skudai, Johor, Malaysia

3 Process Systems Engineering Centre (PROSPECT), Faculty of Engineering, Universiti Teknologi Malaysia, 81310 Skudai, Johor, Malaysia

4 Department of Chemistry, Faculty of Sciences, Benue State University, Makurdi, Benue State P. M. B 102119, Nigeria

5 Department of Mechanical Engineering, Faculty of Engineering, University of Malaya, 50603 Kuala Lumpur, Malaysia

6 Dpto. Matemática Aplicada, Ciencia e Ingeniería de Materiales y Tecnología Electrónica, Universidad Rey Juan Carlos, C/ Tulipán s/n, Móstoles, Madrid, Spain

\section{Introduction}

The airborne PMs and microbial contamination in operating rooms (ORs) are highly related to human activities such as medical staffs' posture, exchanging surgical tools, door movements, and supplying equipment to the scrubbed team during surgery (Kamar et al. 2020; Lin et al. 2020). For example, the $45^{\circ}$ bending posture of medical staff could interrupt the ceiling-mounted airflow, which increases the microbial contamination at the surgical zone 10 fold compared to an upright postured colleague (Chow and Wang 2012). Furthermore, opening doors could result in the loss of positive room pressure and subsequently cause the airborne contaminations from adjacent rooms or corridors to penetrate the OR (Mckenna et al. 2019; Sadrizadeh et al. 2018). A recent study reported that the complexity of surgery is closely related to the presence of airborne contaminants due to the time-consuming nature of surgical procedures that involve more medical staff (Karlatti and Havannavar 2016). Thus, a patient that undergoes complex surgery is prone to contracting a surgical site infection (SSI). This is due to the higher probability of 
microbial contamination of the patient's wound due to prolonged exposure to the surrounding environment (Dexter et al. 2019; Karlatti and Havannavar 2016). In a clean and controlled environment, it is estimated that nearly 3 to $5 \%$ of patients who have undergone surgery developed SSIs (Singh et al. 2014). The infection rates are expectedly higher in lowand middle-income countries that utilise unhygienic OR environment (Allegranzi et al. 2016; McDonald and Bott 2020). Recent statistics show that the total SSI rates for different surgeries are markedly high at $36 \%$ in France (Penel et al. 2008), $33 \%$ in Vietnam (Viet Hung et al. 2016), $28 \%$ in Japan (Morikane 2016), and $12 \%$ in Malaysia (Wong and Holloway n.d.). One of the statistics provided by Morikane et al. (2016) shows that the SSI for rectal surgery in Japan is already marked as high as $17.8 \%$, while in England, the SSI for large bowel surgery, small bowel surgery, and pancreatic surgery are recorded as $8.3 \%, 4.9 \%$, and $4.9 \%$, respectively (Elgohari et al. 2013). Sohn et al. (2006) also claimed that Vietnam's SSI for both orthopaedic surgery and neurosurgical are $15.2 \%$ and $8.3 \%$, respectively.

SSI is defined as any infection that follows an operative procedure and occurs at or near the surgical incision site within 30 days of the procedure (Karlatti and Havannavar 2016). So far, SSIs remain a prominent cause of hospital-acquired infection and are responsible for increased mortality, morbidity, risk of readmission, hospital length of stay, and considerable costs (Elmously et al. 2019; McDonald and Bott 2020). Tanner et al. (2009) reported that in the UK, SSIs result in additional costs of $£ 10,523$ per patient to the National Health Service. In the USA, SSI has increased hospitalisation costs by US $\$ 3,000$ to US $\$ 29,000$ per case depending on the type of surgical procedure performed (Magill et al. 2012). The case study presented by Chow and Wang (2012) indicates that the medical care expenses for a patient with a prosthetic joint SSI reached US\$ 100,000. In European hospitals, patients who develop SSI incur treatment costs of about 2 folds higher than patients who do not develop SSI (Badia et al. 2017). Developing an SSI significantly affects the physical and mental health of patients along with a negative impact on their health-related quality of life (HRQoL) (Pinkney et al. 2013).

In an OR, SSI is mainly caused by either pathogenic bacteria or fungi microorganisms (Albukhari et al. 2019). The most common pathogenic bacteria that cause SSI is Staphylococcus aureus (Sadeghian et al. 2020), which predominantly originates from the respiration and shredded skins of surgical staff (Sadrizadeh et al. 2018). Besides Staphylococcus aureus, other pathogenic bacteria such as Pseudomonas aeruginosa, methicillin-resistant Staphylococcus aureus (MRSA), and Enterococcus faecalis are generally present in ORs. The rise in SSIs is attributed to the growing microbial resistance of MRSA, vancomycin-resistant enterococci (VRE), third-generation cephalosporin-resistant Escherichia coli, and imipenem- and quinolone- resistant Pseudomonas aeruginosa through adaptation and evolution (Darouiche 2016). Although pathogenic bacteria are responsible for the majority of SSI, the fungi which are ubiquitous in distribution may also give rise to SSI (Khan and Karuppayil 2012). Cases of fungal contamination that lead to SSI have become increasingly apparent in immunocompromised patients. These incidents have risen in frequency over the last decades. The opportunistic fungi that cause SSI are Candida albicans (Berechet et al. 2019), Cryptococcus, Rhizopus, Scedosporium, Histoplasma, Phycomycetes, and Mucor (Kaya and Yucel 2007). However, these infections remain less frequent than those related to Aspergillus species due to their virulence characteristics and resistance mechanisms to the drug (Figuerola-Tejerina et al. 2020). Although these opportunistic fungal infections are related to the weakened immune system of patients, there is a need to examine this matter since these infections can be serious and, in some cases, fatal. The presence of these opportunistic fungi, which indicates fungal contamination, will deteriorate the hygiene condition of an OR. Hence, the medical staff need to be aware of SSI caused by microbial contamination and implement infection control measures to reduce their occurrence. The onsite sampling of microbes is an effective way to evaluate and monitor the hygiene status of operating rooms.

The opportunistic microbes increase the risk of infection once the pathogens settle on the patient's wound. The physical size of each microbe typically ranges from 7 (PM 7) to $12 \mu \mathrm{m}$ (PM 12) (Madsen et al. 2018). Recent studies indicate that each person with moderate physical activity releases $10^{4}$ skin scales per minute, $10 \%$ of which have microbial contamination (Sadeghian et al. 2020). The microbial contamination of the skin scales is present in the range of 4 to $60 \mu \mathrm{m}$, with a mean aerodynamic diameter of $12 \mu \mathrm{m}$ (Sadeghian et al. 2020). The microbial contaminants have similar size characteristics with particles suspended in air and spread according to the airflow before final deposition on the surfaces (Sadeghian et al. 2020).

Studies involving the reduction of PMs or microbial contamination using various approaches have been conducted extensively. From the ventilation engineering approach, Sadeghian et al. (2020) suggested that a replacement of the conventional surgical lamp with a fan-mounted surgical lamp reduces the contamination level at the surgical site by 77 to $80 \%$. Lin et al. (2020) claimed that the combination of both ceiling-mounted air diffusers and ceiling-mounted exhaust reduces the airborne PMs at the surgical site. McDonald and Bott (2020) reported that the routine use of sterile drapes and surgical gowns for all procedures in the OR could eliminate bacterial contamination from the surrounding environment. The utilisation of body exhaust suits and sterile surgical helmets systems (SSHSs) effectively reduces the airborne contamination on a patient (Moores et al. 2019; Wendlandt et al. 2016; Young et al. 2016). Furthermore, the supply of 
clean air to the surgical site through a portable ultra-clean airflow unit could reduce the airborne contamination surrounding the patient (Casagrande and Piller 2020).

To better control the incidence of SSIs, hospital authorities have adopted sterilisation and disinfection practices before commencing surgical procedures. The purpose is to eliminate any microbes present on various surfaces such as the operating table, trolley tops, surgical lamps, and door handles, among others. In practice, an Environmental Protection Agency (EPA)-approved disinfectant is typically used to disinfect all surfaces (Mathur 2019). Furthermore, blood and other bodily fluid spills are promptly scrubbed and sterilised using sodium hypochlorite solution. However, for the decontamination of small spills $(<10 \mathrm{ml})$ and more significant spills $(>10 \mathrm{ml})$, the dilution ratios of $1: 100$ or $1: 10$ of 5.25 to $6.15 \%$ sodium hypochlorite are required, respectively (Mathur 2019). In some hospitals, periodic sampling is conducted to trace or monitor the presence of microbial contamination in an OR. Typically, very low or zero microbial levels could prevent a patient from contracting an SSI. However, this practice could interrupt the movement of medical staff during the surgical procedure, particularly when the sampling result is not available instantly.

Vast studies focus on the measurement of airborne particles to represent the sampling of microbial contamination. Mirhoseini et al. (2015) recommended that the measurement of airborne particles is a good approach for continuously monitoring the air quality in both ORs and ICUs. This submission is based on the significant correlation that was observed between microbial contamination and PM 1 to PM 5 (Mirhoseini et al. 2015). To date, the relationship between the PMs and microbes in an OR has scarcely been examined in the literature. Correlation studies between airborne PMs and microbes have been extensively performed in the ambient air of a residential site. However, there was no obvious correlation identified between the microbes and PM 1, PM 2.5, and PM 10 (Raisi et al. 2010). Cristina et al. (2012) conducted a correlation study on the mixing airflows of two PM sizes: PM 0.5 and PM 5 in ORs. The authors observed that the relationship between the microbes and both PM 0.5 and PM 5 is insignificant, whereas larger-sized PM samples such as PM 10 and PM 20 could provide a closer relationship with microbes. The authors further proposed that future investigations should be performed in ORs equipped with unidirectional airflow ventilation systems. The reason is that the unidirectional airflow ventilations widely utilised in modern ORs are more efficient in removing the airborne PMs from surgical sites compared to the mixing airflow ventilation system.

Systematic procedures such as verifying the relative humidity (RH), room differential pressure, air temperature, and air change rate $(\mathrm{ACH})$ function as recommended by the policies and procedures on infection control by the Ministry of Health (MoH) Standard (2010), International Organization of
Standardization (ISO) 14644-1 Standard (1999), IEST Standard (1997), and Standard NEBB (2009) are extremely important. The failure to achieve the recommended operating conditions in an OR could affect the validity and reliability of the correlation assessment between PMs and microbial counts. An effective strategy in reducing SSIs is through the proper implementation and practice of policies and procedures on infection control by healthcare providers. A better understanding of OR heating, ventilating, and air conditioning (HVAC) system and proper disinfection procedures could help to maintain the air quality conditions in an OR and simultaneously minimise the occurrence of SSIs (Spagnolo et al. 2013). ISO 14644-1, IEST, and NEBB guidelines provide the standard procedure for verifying the operating parameters of cleanrooms. The verification procedures include the measurement of room pressurisation, airflow velocity and volume test, airborne particle count, temperature, and RH in an OR. To the best of the authors' knowledge, none of the reviewed literature has proposed, adopted, or employed any systematic procedure in carrying out PM-microbial count correlation studies. Hence, there is an urgent need to re-evaluate the relationship(s) between the PMs and microbial counts. The objective of this study is to develop a systematic procedure for assessing the relationship between PMs and microbial counts. The measurements of the PMs and sampling of the microbes were conducted in four (4) ORs that utilise unidirectional airflow ventilation systems.

\section{Methods}

\section{Details of the operating rooms}

In the present study, four ORs were selected at a private hospital located on the western coast of Peninsular Malaysia (latitude: $2.7258^{\circ} \mathrm{N}$ and longitude: $101.9424^{\circ} \mathrm{E}$ ). The four ORs are classified as ISO Class 7 cleanrooms designated for performing general and orthopaedic surgeries. Currently, cardiothoracic surgeries (i.e. coronary artery bypass grafting, congenital heart surgery, heart transplant, and myotomy), which require strict room cleanliness, are performed in the selected ORs. Each OR, with volume $V=103 \mathrm{~m}^{3}$, is furnished with an identical ventilation system. Each OR has six air supply diffusers that provide clean air. The diffusers are mounted on the ceiling, and the fresh air is supplied in a uniform and vertically downward direction. The arrays of the diffusers are arranged in the barrier form, which extends by a minimum of $305 \mathrm{~mm}$ beyond the footprint on each side of the operating table.

Each diffuser is fitted with type $\mathrm{E}$ high-efficiency particulate air (HEPA) filters that are capable of trapping $99.97 \%$ of particles with a diameter larger than $0.3 \mu \mathrm{m}$. The use of the HEPA filters at the air supply diffuser managed to prevent 
invasive pulmonary aspergillosis in immune-compromised patients (Oren et al. 2001). The contaminated air is then evacuated through four grilles mounted on the sidewalls at the corners of the ORs. The exhaust grilles are placed at a height of $0.4 \mathrm{~m}$ above the floor level. To the best of the authors' knowledge, almost all private hospital ORs in Malaysia employ low-level exhaust grilles. The purpose is to ensure that the larger and heavier PMs are easily removed from the OR. Each of the air supply diffusers and exhaust grilles has a dimension of $1.2 \mathrm{~m} \times 0.6 \mathrm{~m}$ (width $\times$ length) and $0.22 \mathrm{~m} \times 0.46$ $\mathrm{m}$ (width $\times$ height), respectively.

\section{Onsite measurements and sampling guidelines}

This study proposes the use of systematic procedures for conducting onsite measurement and sampling works. All the onsite measurements and samplings procedures were performed following the ISO 1444-3 (Standard 2005), IESTRP-CC006.2 (Standard 1997), and NEBB Procedural Standards for Certified Testing of Cleanroom (Standard 2009). The ORs were purged at least $12 \mathrm{~h}$ before the onsite measurements and samplings were conducted. All the data were logged under the at-rest condition in compliance with the ISO 14644-1 (Standard 1999) guidelines. According to these procedures, a cleanroom is considered at rest when it is fully furnished and in the original condition with no personnel present. No surgical procedure was performed inside the ORs for at least $12 \mathrm{~h}$ before the samplings were performed. To achieve a steady-state operating condition, the ventilation system was switched on $24 \mathrm{~h}$ before samplings. The personnel in charge were required to wear a cleanroom garment throughout the measurement procedures. The dress code consisted of a gown, mask, hood, and pair of boots that fulfilled the cleanroom garment specifications as described in the standard (Standard 2009).

\section{Verification of the operating parameters}

Before the PM measurements and microbial sampling, the operating parameters, namely (i) air change rate $(\mathrm{ACH})$, (ii) room differential pressure, (iii) relative humidity $(\mathrm{RH})$, and (iv) air temperature was verified to ensure the indoor environment of the four ORs has fulfilled the specifications recommended in the policies of Ministry of Health Standard (2010). These operating parameters should be taken into consideration as indicators of the presence or growth rate of the microorganisms. This systematic verification process is of paramount importance to ensure the validity and reliability of PM measurement and microbial sampling data for subsequent correlation assessment. The Alnor EBT 731 balometer with a flow hood (ALNOR, Huntingdon Beach, CA, USA) was used to determine the airflow volume and room pressure differential. The accuracy of the balometer on airflow and differential pressure measurements are $\pm 3 \%$ and $\pm 0.025 \mathrm{~Pa}$, respectively. The RH and air temperature were evaluated using the Testo 625 digital thermo-hygrometer (Testo Inc., Lenzkirch, Germany). The accuracy of the thermo-hygrometer on $\mathrm{RH}$ and air temperature measurements is $\pm 2.5 \%$ and $\pm 0.5^{\circ} \mathrm{C}$, respectively. All the measurement devices were calibrated in compliance with the ISO 9001: 2015 standard.

To promote adequate fresh and clean airflow into an indoor environment, an ISO Class 7 OR should have an air change rate of $\geq 20$ times the room volume in an hour (Standard 1999). This practice improves indoor air quality and potentially reduces the rate of SSIs. A low air ACH could cause stagnant airflow and increased microbial counts. In an OR, the $\mathrm{ACH}$ calculation depends on the room pressurisation. The $\mathrm{ACH}$ in a positive pressure $\mathrm{OR}$ is calculated based on the clean air volume supplied into the room (Wong et al. 2017). However, the $\mathrm{ACH}$ for a negative pressure room is measured based on the exhaust airflow volume (Standard 2009). In this study, the four ORs have positive pressure, and the ACH can be calculated via Equation (1) (Standard 2009):

Air change rate per Hour $(A C H)$

$$
=\frac{\text { Total supply air }\left(\frac{\mathrm{m}^{3}}{\mathrm{~min}}\right) \times 60}{\text { Room volume }\left(\mathrm{m}^{3}\right)}
$$

The Alnor EBT 731 Balometer equipped with a flow hood has been widely employed for quantifying the airflow in an OR, which is fitted with ceiling-mounted diffusers. The balometer has the advantage of measuring the airflow volume at the large nominal face area of the air supply diffuser. For airflow volume measurement, a hood size that fits closely to the open area of the air supply diffuser was selected. The absence of a gap between the capture hood and the surface around the diffuser prevented any air leakage. All the airflow volume measurements were logged after achieving the steadystate condition. The onsite measurements of the airflow volume were achieved using the balometer and the capture hood at the supply diffuser, as shown in Fig. 1.

Upon verifying that the $\mathrm{ACH}$ fulfils the minimum requirements of an ISO Class $7 \mathrm{OR}$, the next procedure is to ensure that the ORs are in positive pressure when compared to the adjacent zones, namely, the airlock room and corridor. The purpose is to create a barrier at the gap between the OR doors to prevent the penetration of airborne particles or microbial contamination. The differential pressure between the OR and adjacent zones was measured using the Alnor EBT 731 balometer.

During the measurement of the differential pressure, the main device was held in the OR, while the sensor on the connection pipe was placed in the adjacent zones. All the doors to the ORs were closed to avoid any changes in the 


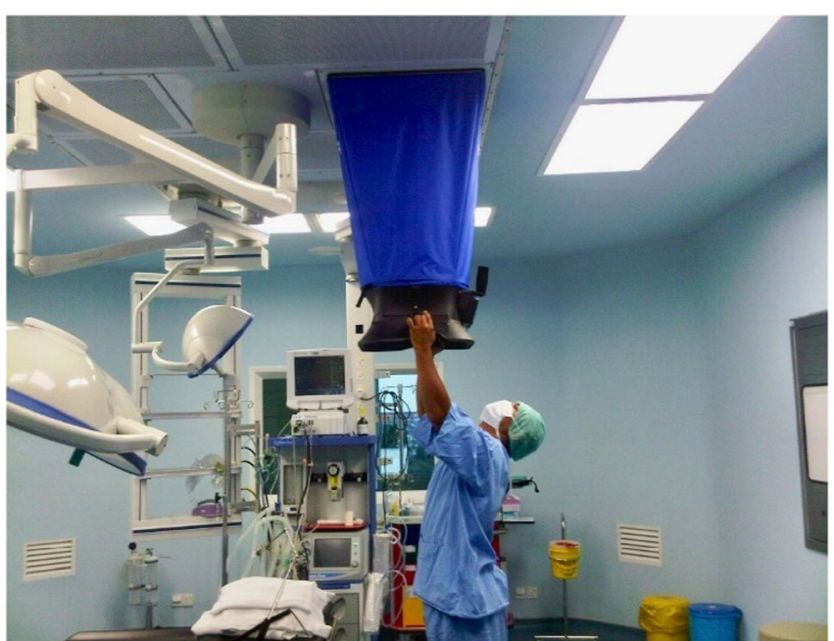

Fig. 1 Measurement of airflow volume using the balometer with capture hood

airflow direction and increment in air temperature caused by door-opening or door-closing movements. The positive pressure could drop from 6 to $0 \mathrm{~Pa}$ within $1 \mathrm{~s}$ due to a dooropening or door-closing activity (Zhou et al. 2018). Sadrizadeh et al. (2018) reported that frequent door opening and closing increases the airborne contaminants in an OR by 7 $\mathrm{cfu} / \mathrm{m}^{3}$. Other studies have also demonstrated that there is a positive correlation between the door opening or closing and the microbial counts in an OR (Andersson et al. 2012; Smith et al. 2013; Teter et al. 2017). The onsite measurement of pressure differential is shown in Fig. 2. The differential pressure data of each OR were logged after achieving the required steady-state condition.

The digital thermo-hygrometer (Testo 625, Lenzkirch, Germany) was used to measure the air temperature and RH. To measure the two parameters, the ORs were divided into six sampling grids according to the IEST standard (Standard 1997). The air temperature and RH measurements were performed simultaneously for each sampling grid. The probe of the thermo-hygrometer was positioned at the centre of the sampling grid at a height of $1.1 \mathrm{~m}$ above the floor level. The

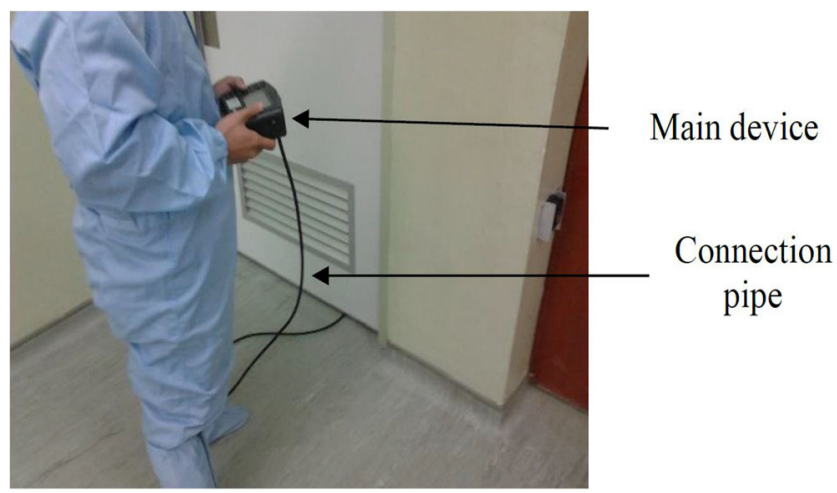

Fig. 2 Measurement of room pressure differential using the balometer with a connection pipe (Wong 2019) generated sampling grids in the four ORs are shown in Fig. 3. The minimum numbers of sampling grids were calculated from Equation (2), and each test grid should be smaller than $30 \mathrm{~m}^{2}$ (Standard 1997).

$N=\sqrt{A}$

where $N$ is the minimum number of sampling grids and $A$ is the area of a cleanroom in square metres. For an ISO Class 7 OR that has a floor area below $150 \mathrm{~m}^{2}$, it is a common practice to generate 6 grids for measurements purposes.

\section{Airborne particulate matter measurements}

The TSI 9510-02 particle counter was used to measure the PMs. The particle counter was calibrated in compliance with the ISO 21501: 2018 standard. Three different particulate matter sizes, PM 0.5, PM 5, and PM 10, were measured in this study. The particle sizes below PM 0.5 were not considered since previous studies have claimed that there is no relationship with microbial counts. However, a noticeable relationship between PM 0.5 or larger and microbial counts was reported in correlation studies (Cristina et al. 2012; Pasquarella et al. 2020; Wong et al. 2018). The probe of the particle counter was placed at a height of $1.1 \mathrm{~m}$ above floor level. The PMs concentration was measured at the defined sampling grids shown in Fig. 4.

\section{Active microbial samplings}

The two types of microbial sampling techniques widely used by researchers are active sampling and passive sampling. The former approach requires the use of a mechanical device to draw air through an air sample container, while the latter relies on the effect of molecular diffusion. Perdelli et al. (2000) claimed that the microbial concentrations obtained by both active and passive samplings are quite similar. Furthermore, active microbial sampling was shown to be as effective as passive microbial sampling (Perdelli et al. 2000). However, in the present study, passive microbial sampling was not conducted, as this approach requires a longer sampling time.

The active microbial sampling was performed using the MAS-100ECO air sampler at a flow rate of $100 \mathrm{l} / \mathrm{min}$. The sampling was performed within $1 \mathrm{~m}$ of the operating table. This distance is the recommended position to sample microbial contamination as the Petri plates are located nearer to the wound of the patient (Napoli et al. 2012). A volume of 5001 of air was sampled under the "at rest" condition in one continuous drawing. Under this condition, which is without the presence of any personnel in the ORs, the results of the samplings reflect mainly on the performance of the ventilation system (Napoli et al. 2012; Pasquarella et al. 2008; Standard 2003). A 90-mm diameter Petri plate with Tryptic Soy Agar (TSA) was 
Fig. 3 Sampling grids for a OR 1, b OR 2, c OR 3, and d OR 4

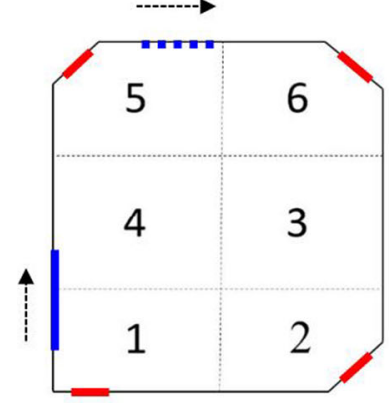

(a)

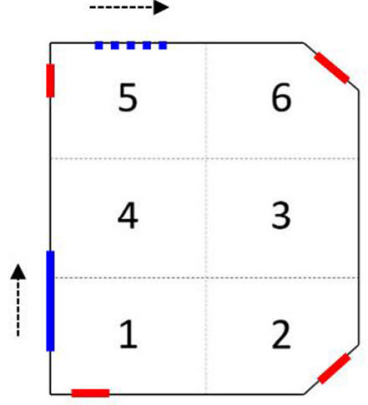

(b)

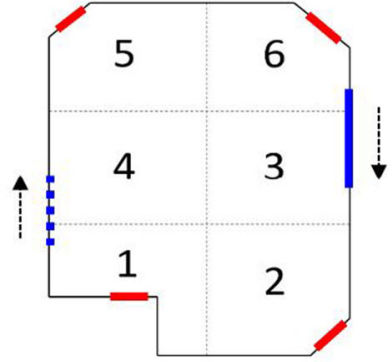

(c)

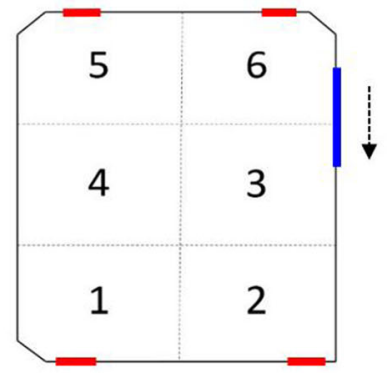

(d)

used to obtain the total bacteria intensities, while Sabouraud Dextrose Agar (SDA) was used to determine the total fungal count. After completing the samplings, the samples were outsourced to a microbiology facility for analysis. The TSA and SDA plates were incubated at $35^{\circ} \mathrm{C}$ for 2 days and $30^{\circ} \mathrm{C}$ for 10 days, respectively. The TSA plates were used to identify Staphylococcus aureus since it is the most common causative agent for SSIs. The total microbial count is the sum of the bacteria and fungi quantities (measured in $\mathrm{cfu} / \mathrm{m}^{3}$ ). According to the policies and procedures on infection control of the Ministry of Health Malaysia (Standard 2010), the maximum acceptable counts of bacteria and fungi present in an ISO Class 7 OR must be less than or equivalent to $35 \mathrm{cfu} / \mathrm{m}^{3}$.

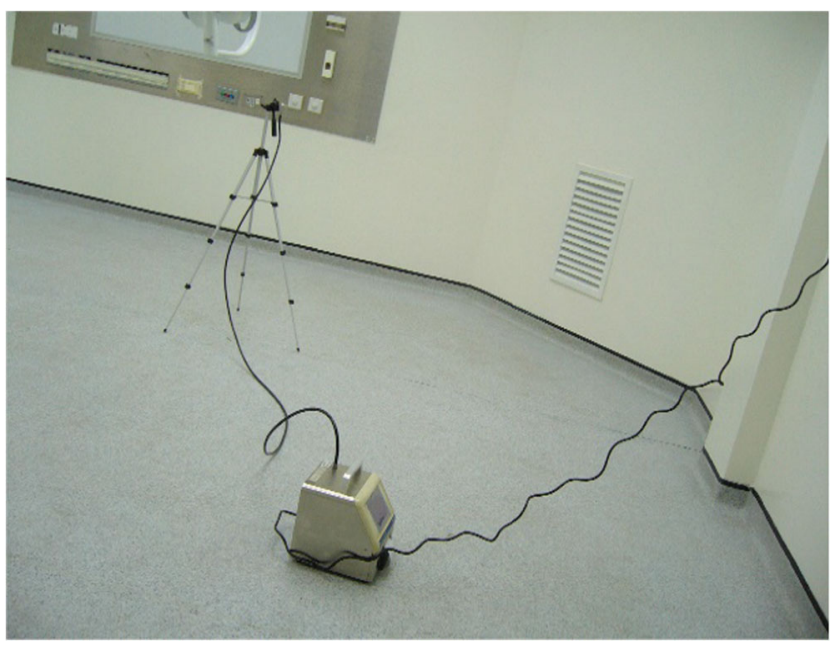

Fig. 4 Samplings of PMs using the airborne particle counter
The samplings of bacteria and fungi using the air sampler are shown in Fig. $5 a$ and b, respectively.

\section{Error analysis and correlation percentage calculations}

The reliable estimation of errors is an important aspect of conducting field measurements to ensure the validity of the measured parameters (Wong et al. 2018). There are two types of error, namely, systematic and random errors. Systematic errors are reproducible inaccuracies that are consistent regardless of the number of measurements. Random errors are statistical fluctuations in the measured data due to the precision limitations (Deardorff 2000). Before the measurement, the measurement device and sampling instrument used were calibrated to eliminate systematic errors. To reduce the effects of random errors, three repeated measurements were conducted at each sampling location. The uncertainty or standard deviation, $\sigma$, was used to estimate the uncertainty associated with each measurement. Its expression is given in Equation (3) (Annoni 2012).

$\sigma=\sqrt{\frac{\sum_{i=1}^{n}\left(x_{i}-\dot{x}\right)^{2}}{n-1}}$

where $\sigma$ is the standard deviation; $n$ is the number of measurements of the data; $\ddot{x}$ is the sample mean; and $x_{i}$ is the measurement value. For error analysis, the parameter is normally expressed as $x=\ddot{x} \pm \sigma$. Equation (4) expresses the correlation percentage for assessing the influence of PM on microbial 
Fig. 5 Sampling of a bacteria using air sampler with TSA and $\mathbf{b}$ fungi using air sampler with SDA

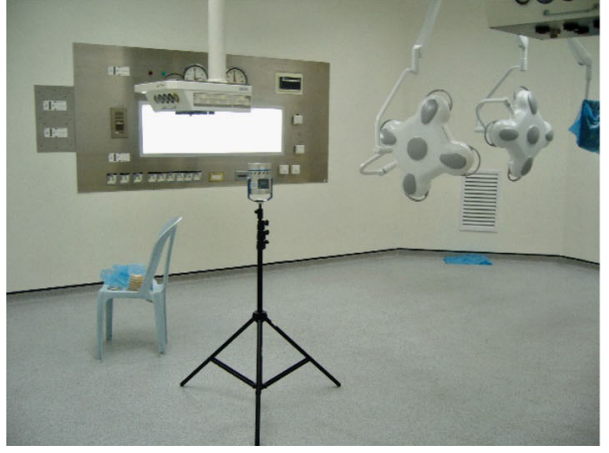

(a)

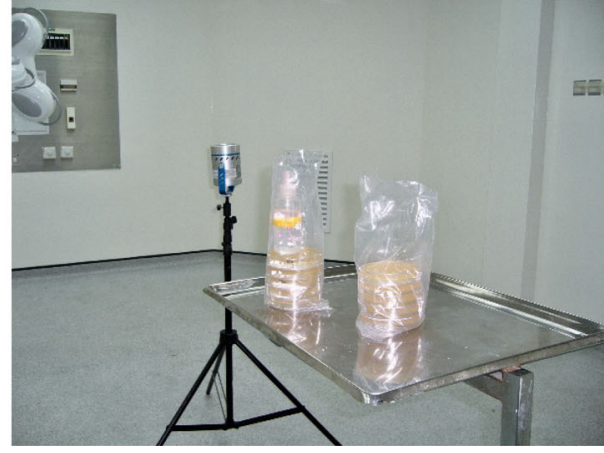

(b) quantities (Wong et al. 2018), where $n$ denotes the number of ORs.

Correlation percentage

$$
=\frac{\left(\frac{\text { Microbial counts }}{\text { PM counts }}\right)_{1}+\left(\frac{\text { Microbial counts }}{\text { PM counts }}\right)_{2}+\ldots+\left(\frac{\text { Microbial counts }}{\text { PM counts }}\right)_{n}}{n} \times 100 \%
$$

\section{Results and discussion}

Based on the measured airflow volume, the calculated ACH in the four ORs fulfilled the minimum requirement of $20 / \mathrm{h}$. The ACH obtained from the four ORs ranges from 29 to 40/hr. This ACH indicates that the air supplied into the OR is sufficient for the occupants. An air change of $15 \mathrm{ACH}$ is insufficient to reduce the microbial counts in an OR with a unidirectional airflow system. The microbial counts exceeded the Italian National Institute for Occupational Safety and Prevention (ISPESL) recommended guidelines by 1.5 times (Wagner et al. 2019). In the USA, most hospitals practice with an $\mathrm{ACH}$ of $\geq 25$ to provide optimum clean air to the OR occupants. The study proved that increasing the air change from 20 to $25 \mathrm{ACH}$ could reduce the microbial counts in an OR by approximately 1.5 times (Parvizi et al. 2017). Liang et al. (2020) also found out that an air change of 20-30 ACH managed to reduce the PM 2.5 and PM 10 concentrations in compliance with the indoor air quality standards of Taiwan. Practising with a high ACH also improved clinical outcomes in an OR with great potential to reduce the SSIs (Gormley et al. 2017), although increasing the air exchange rate by 5 $\mathrm{ACH}$ increases operational costs to US\$ 7000 per OR annually. However, Gormley et al. (2017) stated that the patient's safety is the utmost consideration. The measured airflow volume for each diffuser and the room differential pressure in the four ORs are tabulated in Table 1.

Based on Table 1, the room differential pressure measurements in all four ORs have a differential pressure of at least
+6.86 Pa concerning the airlock room. However, a minimum differential pressure of at least +9.17 Pa concerning the corridor was obtained. Thus, the four ORs met the requirement of $\geq$ $5 \mathrm{~Pa}$, as stated in the policies and procedures on infection control (Standard 2010). The positive room differential pressure indicates that there is no intrusion of airborne PMs or microbes from the adjacent zones.

For an OR utilising the turbulent-mixing ventilation system, the room differential pressure should be maintained at a higher pressure of approximately $15 \mathrm{~Pa}$ (Sadrizadeh et al. 2018). A negative pressure OR will be used for the case where a patient is suspected or infected with a respiratory virus such as severe acute respiratory syndrome (SARS) (Chow et al. 2006) and Middle East respiratory syndrome coronavirus (MERS-CoV) (Park et al. 2020). When an infected patient undergoing a surgical procedure under a negative pressure of $-4.7 \mathrm{~Pa}$ is maintained in an $\mathrm{OR}$, the transmission of the virus to the surrounding environment and adjacent zones could be prevented (Park et al. 2020).

Based on Table 2, the measured data of the air temperature and $\mathrm{RH}$ are within the recommended ranges of $18-22^{\circ} \mathrm{C}$ and $50-60 \%$, respectively. However, an RH of greater than $60 \%$ will cause the air moisture to be absorbed into the OR walls and other surfaces. This occurrence will promote the growth of microbial contaminants and increase the risk of a patient contracting an SSI. The findings of Canadian hospitals showed that when ORs were prescribed an RH below $60 \%$, the SSI rate was between 3.3 and $5.6 \%$ (Bruce et al. 2007) but increased to $10.7 \%$ at an $\mathrm{RH}$ of 60 $85 \%$ (Bruce et al. 2007). A low RH environment, however, could cause an electrostatic shock when medical staff are exposed to electro-medical devices. An air temperature higher than $22{ }^{\circ} \mathrm{C}$ is commonly reported to cause the adhesive cement for orthopaedics surgery to set rapidly. Furthermore, the medical staff who are equipped with multiple layers of safety gowns experienced thermal discomfort when undergoing lengthy surgical procedures. The measured air temperature and $\mathrm{RH}$ data for the ORs are shown in Table 2. 
Table 1 Airflow volume, $\mathrm{ACH}$, and room differential pressure

\begin{tabular}{|c|c|c|c|c|c|c|c|c|c|c|}
\hline \multirow[t]{3}{*}{ Room } & \multicolumn{6}{|c|}{ Airflow volume $\left(\mathrm{m}^{3} / \mathrm{min}\right)$} & \multirow[t]{3}{*}{ Total air volume $\left(\mathrm{m}^{3} / \mathrm{min}\right)$} & \multirow[t]{3}{*}{ Air change rate $(/ \mathrm{hr})$} & \multirow[t]{3}{*}{ Location } & \multirow[t]{3}{*}{ Differential pressure $(\mathrm{Pa})$} \\
\hline & \multicolumn{6}{|c|}{ Diffuser } & & & & \\
\hline & 1 & 2 & 3 & 4 & 5 & 6 & & & & \\
\hline \multirow[t]{2}{*}{ OR 1} & 9 & 12 & 13 & 13 & 10 & 12 & 69 & 40 & With respect to corridor & +17.53 \\
\hline & & & & & & & & & With respect to the airlock room & +14.91 \\
\hline \multirow[t]{2}{*}{ OR 2} & 7 & 11 & 11 & 9 & 10 & 8 & 56 & 33 & With respect to corridor & +13.97 \\
\hline & & & & & & & & & With respect to the airlock room & +6.86 \\
\hline \multirow[t]{2}{*}{ OR 3} & 6 & 8 & 8 & 10 & 8 & 9 & 49 & 29 & With respect to corridor & +9.17 \\
\hline & & & & & & & & & With respect to the scrub room & +7.20 \\
\hline OR 4 & 11 & 8 & 10 & 9 & 8 & 8 & 54 & 32 & With respect to corridor & +17.07 \\
\hline
\end{tabular}

Based on the measured data, the $\mathrm{ACH}$, room differential pressure, air temperature, and $\mathrm{RH}$ has fulfilled the recommended ranges as stated in the policies and procedures on infection control by the Ministry of Health Standard (2010). Although the operating parameters were inconsistent throughout the measurement data, the values met the specification and fall within the proposed range. Therefore, it can be inferred that the variation in operating parameters provides a negligible effect on the correlation assessment and all the ORs are in ideal operational conditions.

The PMs and microbial samplings data show the mean concentrations of the three types of PMs are below the threshold values prescribed in the ISO Class 7 standard (Standard 1999). The total concentrations of microbes also met the guidelines set by the Policies and Procedures on Infection Control Standard (2010). According to the Environmental Monitoring of Clean Rooms Standard ( 2012) of the World Health Organization and Policies and Procedures on Infection Control Standard (2010) of the Ministry of Health Malaysia, the total microbial count in the cleanroom consists of bacteria and fungi only. Previous studies identified that the contraction of SSIs by patients was due to the settlement of bacteria of their wounds (Carvalho et al. 2017; Jentzsch et al. 2021). To the best of the author's knowledge, none of the studies reported the presence of a virus (which are also microbes) in an OR. The measured concentrations of PM 0.5, PM 5, PM 10, bacteria, and fungi are shown in Table 3.

Table 3 shows that the microbes in the ORs contain bacteria without the presence of fungi. This finding is quite common when the sampling is performed in an OR equipped with a HEPA filtration system (Sivagnanasundaram et al. 2019). The reason is that the filtration system managed to trap the fungi, which physically appears larger than the bacteria. Li and Hou (2003) investigated the microbial quality of 100 cleanrooms in various hospitals. The authors also discovered that no fungi were identified, while bacteria counts were detected in the cleanrooms. The study performed by Sarica et al. (2002) in Turkey also reported higher concentrations of bacteria compared to fungi. The random errors associated with the PM measurement are shown in Table 4.

The percentage correlation between the PM sizes and the microbial counts are shown in Fig. 6. The findings show that

Table 2 Measured air temperature and RH in four ORs

\begin{tabular}{|c|c|c|c|c|c|c|c|c|}
\hline \multirow{2}{*}{$\begin{array}{l}\text { Sampling } \\
\text { point }\end{array}$} & \multicolumn{2}{|l|}{ OR 1} & \multicolumn{2}{|l|}{ OR 2} & \multicolumn{2}{|l|}{ OR 3} & \multicolumn{2}{|l|}{ OR 4} \\
\hline & $\begin{array}{l}\text { Temperature } \\
\left({ }^{\circ} \mathrm{C}\right)\end{array}$ & $\begin{array}{l}\text { Relative } \\
\text { humidity (\%) }\end{array}$ & $\begin{array}{l}\text { Temperature } \\
\left({ }^{\circ} \mathrm{C}\right)\end{array}$ & $\begin{array}{l}\text { Relative } \\
\text { humidity (\%) }\end{array}$ & $\begin{array}{l}\text { Temperature } \\
\left({ }^{\circ} \mathrm{C}\right)\end{array}$ & $\begin{array}{l}\text { Relative } \\
\text { humidity }(\%)\end{array}$ & $\begin{array}{l}\text { Temperature } \\
\left({ }^{\circ} \mathrm{C}\right)\end{array}$ & $\begin{array}{l}\text { Relative } \\
\text { humidity (\%) }\end{array}$ \\
\hline 1 & 18.5 & 57.8 & 18.6 & 57.5 & 19.1 & 54.9 & 21.7 & 51.0 \\
\hline 2 & 18.5 & 57.9 & 18.6 & 58.5 & 19.1 & 54.7 & 21.1 & 59.0 \\
\hline 3 & 18.5 & 58.0 & 18.4 & 55.5 & 19.3 & 54.1 & 21.7 & 53.1 \\
\hline 4 & 18.4 & 57.3 & 18.5 & 57.5 & 19.2 & 54.2 & 21.7 & 53.1 \\
\hline 5 & 18.6 & 57.6 & 18.6 & 55.5 & 19.1 & 53.6 & 21.5 & 51.1 \\
\hline 6 & 18.6 & 57.4 & 18.6 & 56.5 & 19.3 & 53.9 & 21.6 & 52.1 \\
\hline Average & 18.5 & 57.7 & 18.6 & 56.8 & 19.2 & 54.2 & 21.6 & 53.2 \\
\hline
\end{tabular}


Table 3 Average concentrations of particulate matter and microbial counts in the four ORs.

\begin{tabular}{|c|c|c|c|c|c|c|}
\hline \multirow[t]{2}{*}{ Location } & \multicolumn{3}{|c|}{$\begin{array}{l}\text { Concentrations } \\
\text { (particles } / \mathrm{m}^{3} \text { ) }\end{array}$} & \multicolumn{3}{|c|}{$\begin{array}{l}\text { Concentrations } \\
\left(\mathrm{cfu} / \mathrm{m}^{3}\right)\end{array}$} \\
\hline & PM 0.5 & PM 5 & PM 10 & Bacteria & Fungi & Total microbes \\
\hline OR 1 & 12,862 & 536 & 225 & 23 & 0 & 23 \\
\hline OR 2 & 21,631 & 100 & 53 & 12 & 0 & 12 \\
\hline OR 3 & 7,944 & 595 & 293 & 31 & 0 & 31 \\
\hline OR 4 & 8,498 & 118 & 41 & 6 & 0 & 6 \\
\hline $\begin{array}{l}\text { ISO 14644-1/Policies and Procedures } \\
\text { on Infection Control }\end{array}$ & 352,000 & 2,930 & N/A & 35 & 35 & N/A \\
\hline
\end{tabular}

PM 0.5 does not possess any clear correlation with microbial intensities. The microbial counts were significantly lower than the mean PM 0.5 in the four ORs with the correlations ranging from 0.02 to $0.3 \%$. This finding is in good agreement with 23 studies conducted by Scaltriti et al. (2007) in 3 mixing ventilation ORs. The authors claimed that $98 \%$ of the measured PM 0.5 is fine dust load suspended in the air but with no positive relationship with the microbes. The authors further stated that the PM 0.5 concentrations are an indicator of the duration of surgical procedures, where the concentration and operation time are directly proportional. Likewise, a recent study identified that the airborne microbes present in a standard atmospheric environment are at least $2 \mu \mathrm{m}$ in aerodynamic diameter (Dommergue et al. 2019). One of the dominant microbes that are present in an OR, Staphylococcus aureus, has a diameter ranging from 2.1 to $3.2 \mu \mathrm{m}$ (Lenart-Boroń et al. 2021). Hence, all these findings confirmed that PM 0.5 lacks an apparent positive correlation with the microbial count.

The PM 5 and PM 10 both show a small positive correlation with the microbial amount. On average, the correlation percentages of PM 5 and PM 10 that correspond to microbial levels are $7 \%$ and $15 \%$, respectively. These findings are in

Table 4 Random error for each measured PM

\begin{tabular}{lll}
\hline Location & Particulate matter & Error analysis expression \\
\hline OR 1 & PM 0.5 & $12862 \pm 7460$ particles \\
& PM 5 & $536 \pm 309$ particles \\
OR 2 & PM 10 & $225 \pm 126$ particles \\
& PM 0.5 & $21631 \pm 4247$ particles \\
& PM 5 & $100 \pm 69$ particles \\
OR 3 & PM 10 & $53 \pm 37$ particles \\
& PM 0.5 & $7944 \pm 3351$ particles \\
& PM 5 & $595 \pm 69$ particles \\
OR 4 & PM 10 & $293 \pm 37$ particles \\
& PM 0.5 & $8498 \pm-4604$ particles \\
& PM 5 & $118 \pm 73$ particles \\
& PM 10 & $41 \pm 47$ particles \\
\hline
\end{tabular}

good agreement with Wagner and Schreiber (2014) and Sadrizadeh et al. (2014). Similarly, Wang and Chow (2015) showed that PM 5 or larger have a significant relation with the microbial count. Hence, the authors treated PM 5, PM 6, PM 8, and PM 10 as microbes in simulating the microbial movements in an OR. Fan et al. (2019), however, reported that PM 2.5 has a close relationship with microbial counts, especially with pathogenic bacteria. Based on a study conducted in seven ISO Class 7 ORs, Wong et al. (2018) claimed that PM 5, PM 10 , and PM 25 result in percentage correlations to microbes of $5 \%, 10 \%$, and $20 \%$, respectively. Likewise, a study conducted in Taiwanese ORs indicated that the microbial counts are correlated with PM 5 to PM 7 (Tang and Wan 2013; Wan et al. 2011). However, Memarzadeh and Manning (2002) disagreed with the claim that PM 5 is correlated to microbial counts. In fact, the authors' finding are similar to Palladino et al. (2021), who performed a scrutinised air quality study and suggested that microbes are present in PM 10. So far, there is no consensus on the exact PM size that is correlated to microbial counts.

Low microbial contamination in an OR is critical in controlling SSI. Microbial monitoring can be a useful tool to assess indoor environmental quality and the risks of

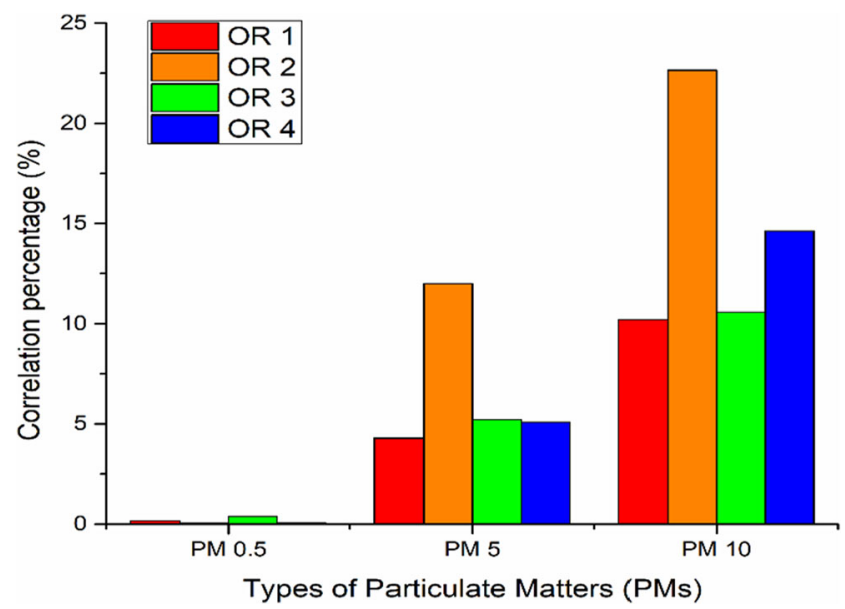

Fig. 6 Correlation percentage between microbes and PMs in the four ORs 
contracting an SSI. However, microbial samplings require extended periods to acquire the data compared to the sampling of PMs. The incubation period for the microbial samples at the lab usually requires a few days to complete, while measurement data for PMs are almost immediately available. The setup for microbial samplings could interrupt the movements of the medical staff members and the surgical procedures. Therefore, for frequent indoor air quality monitoring purposes, it is suggested that the monitoring of both PM 5 and PM 10 could be an alternative way to replace microbial monitoring.

The present systematic approach of correlating the PM and microbial counts applies to all cleanrooms and the healthcare facilities that prescribed a positive pressure environment. This correlation approach, however, is not applicable in healthcare facilities that have a negative pressure environment, i.e. negative pressure isolation room, negative pressure operating room, and negative pressure patient ward. Likewise, it is not suitable for implementation in the healthcare facilities that cater for virally infected patients such as SARS, MERSCoV, SARS-CoV-2 (COVID-19), or similar airborne virus infections. The referred set of standards and guidelines are designed to prevent the entrainment of pathogenic microbes or PM from adjacent zones into the healthcare facilities by prescribing a positive pressure environment. The implementation of the present approach in the negative pressure environment will invalidate the findings. This is due to the improper method used to determine operating parameters such as air change rate and airflow volume. To study the applicability of the present method to the COVID-19 virus, a more carefully designed study is needed to protect the operating personnel during the experiments. Such possibility will be explored in the near future.

\section{Conclusions}

The article presented a systematic procedure for evaluating the relationship between PMs and microbial contamination using onsite measurements and microbes sampling in four ORs. Before the onsite measurements and sampling work, the four ORs are verified to operate under the specifications as stated in the policies by the Ministry of Health Malaysia. According to the ISO norms, the findings show that the concentration of PM 0.5 has no mutual correlation to the microbial level under the "at rest" conditions. However, both PM 5 and PM 10 show a positive relationship to microbial levels of $7 \%$ and $15 \%$, respectively. Hence, PM 5 and PM 10 show a noticeable correlation with microbial counts. The measurement data of PM 5 and PM 10 can be used for general monitoring of microbial contamination in ORs, as the routine surveillance programmes before the commencement of each surgical procedure. In future studies, the authors recommend the PM measurements and microbial samplings are conducted during surgery (or under "in operational" conditions) to reflect real contamination in the OR. It is also prudent to adopt a larger sample size to obtain more reliable correlation percentages to reduce the margin of error.

Author contribution Conceptualization, methodology, and writing (original draft), Huiyi Tan; methodology, supervision, and review and editing, Keng Yinn Wong; writing and review and editing, Bemgba Bevan Nyakuma and Haslinda Mohamed Kamar; resources and conceptualization, Wen Tong Chong; investigation and review and editing, Syie Luing Wong and Hooi Siang Kang

Funding The authors would like to acknowledge Universiti Teknologi Malaysia for the UTMER grant with VOT number: 19J15 that was provided for this research study.

Data availability Not applicable.

\section{Declarations}

Ethics approval and consent to participate Not applicable.

Consent for publication Not applicable.

Competing interests The authors declare no competing interests.

\section{References}

Albukhari TA, Nafady-Hego H, Elgendy H, Abd Elmoneim HM, Nafady A, Alzahrani AM (2019) Analysis of bacterial and fungal infections after cytoreduction surgery and hyperthermic intraperitoneal chemotherapy: an observational single-centre study. Int J Microbiol 2019: $1-10$

Allegranzi B, Zayed B, Bischoff P, Kubilay NZ, de Jonge S, de Vries F, Gomes SM, Gans S, Wallert ED, Wu X (2016) New WHO recommendations on intraoperative and postoperative measures for surgical site infection prevention: an evidence-based global perspective. Lancet Infect Dis 16:e288-e303

Andersson AE, Bergh I, Karlsson J, Eriksson BI, Nilsson K (2012) Traffic flow in the operating room: an explorative and descriptive study on air quality during orthopaedic trauma implant surgery. Am $\mathrm{J}$ Infect Control 40:750-755

Annoni M (2012) Water jet velocity uncertainty in laser Doppler velocimetry measurements. Measurement 45:1639-1650

Badia J, Casey A, Petrosillo N, Hudson P, Mitchell S, Crosby C (2017) Impact of surgical site infection on healthcare costs and patient outcomes: a systematic review in six European countries. J Hosp Infect 96:1-15

Berechet MD, Constantinescu RR, Maria R, Chirila C, Stanca M, Simion D, Surdu L, Gurau DF (2019) Antifungal and antibacterial treatments based on natural compounds for lining leather and footwear articles. Revista de Pielarie Incaltaminte 19:201

Bruce N, Ouellet C, Suh K, Roth V (2007) Does high humidity in the operating room $(\mathrm{OR})$ impact surgical site infection (SSI) rates? Am J Infect Control 35:E191

Carvalho RLR, Campos CC, Franco LMC, ADM R, Ercole FF (2017) Incidence and risk factors for surgical site infection in general surgeries 1. Revista latino-americana de enfermagem 25 
Casagrande D, Piller M (2020) Conflicting effects of a portable ultraclean airflow unit on the sterility of operating rooms: a numerical investigation. Build Environ 171:106643

Chow T-T, Wang J (2012) Dynamic simulation on the impact of surgeon bending movement on bacteria-carrying particles distribution in the operating theatre. Build Environ 57:68-80

Chow TT, Kwan A, Lin Z, Bai W (2006) Conversion of operating theatre from positive to negative pressure environment. J Hosp Infect 64: 371-378

Cristina ML, Spagnolo AM, Sartini M, Panatto D, Gasparini R, Orlando P, Ottria G, Perdelli F (2012) Can particulate air sampling predict microbial load in operating theatres for arthroplasty? PLoS ONE 7: e52809

Darouiche R (2016) Surgical site infections. Hosp Infect Control 9:12-15

Deardorff D (2000) Introduction to measurements and error analysis. University of North Carolina, North Carolina. http:// user.physics.unc. edu...

Dexter F, Ledolter J, Epstein RH, Loftus RW (2019) Importance of operating room case scheduling on analyses of observed reductions in surgical site infections from the purchase and installation of capital equipment in operating rooms. Am J Infect Control

Dommergue A, Amato P, Tignat-Perrier R, Magand O, Thollot A, Joly M, Bouvier L, Sellegri K, Vogel T, Sonke JE, Jaffrezo JL, Andrade M, Moreno I, Labuschagne C, Martin L, Zhang Q, Larose C (2019) Methods to investigate the global atmospheric microbiome. Front Microbiol 10:243

Elgohari S, Mihalkova M, Wloch C (2013) Surveillance of Surgical Site Infections in NHS Hospitals in England, 2013/2014. Public Health England. Health Protection Agency

Elmously A, Gray KD, Michelassi F, Afaneh C, Kluger MD, Salemi A, Watkins AC, Pomp A (2019) Operating room attire policy and healthcare cost: favouring evidence over action for prevention of surgical site infections. J Am Coll Surg 228:98-106

Fan X-Y, Gao J-F, Pan K-L, Li D-C, Dai H-H, Li X (2019) More obvious air pollution impacts on variations in bacteria than fungi and their co-occurrences with ammonia-oxidizing microorganisms in PM2. 5. Environ Pollut 251:668-680

Figuerola-Tejerina A, Hernández-Aceituno A, Alemán-Vega G, OrilleGarcía C, Ruiz-Álvarez M, Sandoval-Insausti H (2020) Developing a faster way to identify biocontamination in the air of controlled environment rooms with HEPA filters: airborne particle counting. Sci Rep 10:1-8

Gormley T, Markel TA, Jones H, Greeley D, Ostojic J, Clarke JH, Abkowitz M, Wagner J (2017) Cost-benefit analysis of different air change rates in an operating room environment. Am J Infect Control 45:1318-1323

Jentzsch T, Kutschke L, Zingg PO, Farshad M (2021) Operating room architecture is not a risk factor for surgical site infections. Sci Rep 11:13391

Kamar HM, Wong KY, Kamsah N (2020) The effects of medical staff turning movements on airflow distribution and particle concentration in an operating room. J Build Perform Simul 13:684-706

Karlatti S, Havannavar I (2016) A comparative prospective study of preoperative antibiotic prophylaxis in the prevention of surgical site infections. Int Surg J 3:141-145

Kaya D, Yucel M (2007) Fungal agents as a cause of surgical wound infections: an overview of host factors. Wounds: a compendium of clinical research and practice 19:218-222

Khan AH, Karuppayil SM (2012) Fungal pollution of indoor environments and its management. Saudi J Biol Sci 19:405-426

Lenart-Boroń A, Drab D, Chrobak J (2021) Microbiological aerosol, particulate matter concentrations and antibiotic-resistant Staphylococcus spp. in the premises of Poland's oldest agricultural school. Atmosphere 12:934

Li C-S, Hou P-A (2003) Bioaerosol characteristics in hospital clean rooms. Sci Total Environ 305:169-176
Liang C-C, Wu F-J, Chien T-Y, Lee S-T, Chen C-T, Wang C, Wan G-H (2020) Effect of ventilation rate on the optimal air quality of trauma and colorectal operating rooms. Build Environ 169:106548

Lin T, Zargar OA, Lin K-Y, Juiña O, Sabusap DL, Hu S-C, Leggett G (2020) An experimental study of the flow characteristics and velocity fields in an operating room with laminar airflow ventilation. J Build Eng 29:101184

Madsen AM, Kurdi I, Feld L, Tendal K (2018) Airborne MRSA and total Staphylococcus aureus as associated with particles of different sizes on Pig Farms. Ann Work Expos Health 62:966-977

Magill SS, Hellinger W, Cohen J, Kay R, Bailey C, Boland B, Carey D, de Guzman J, Dominguez K, Edwards J (2012) Prevalence of healthcare-associated infections in acute care hospitals in Jacksonville, Florida. Infect Control Hosp Epidemiol 33:283-291

Mathur P (2019) Infection control in operating rooms: sterilization and disinfection practices, Textbook of Neuroanesthesia and Neurocritical Care. Springer, pp 351-358

McDonald S, Bott A (2020) Surgical site infections. Surgery (Oxford) 38: $150-154$

Mckenna K, Hutchinson A, Butler M (2019) An evaluation of the environmental factors that impact on operating room air quality and the risk for development of surgical site infections. Infect Dis Health 24: S7

Memarzadeh F, Manning AP (2002) Comparison of operating room ventilation systems in the protection of the surgical site/Discussion. ASHRAE Trans 108:3

Mirhoseini SH, Nikaeen M, Khanahmad H, Hatamzadeh M, Hassanzadeh A (2015) Monitoring of airborne bacteria and aerosols in different wards of hospitals-Particle counting usefulness in the investigation of airborne bacteria. Ann Agric Environ Med 22: 670-673

Moores TS, Khan SA, Chatterton BD, Harvey G, Lewthwaite SC (2019) A microbiological assessment of sterile surgical helmet systems using particle counts and culture plates: recommendations for safe use whilst scrubbing. J Hosp Infect 101:354-360

Morikane K (2016) Incidence and risk factors associated with surgical site infection following different types of hepatobiliary surgery, Open Forum Infectious Diseases. Oxford University Press, pp 1455

Morikane K, Honda H, Yamagishi T, Suzuki S, Aminaka M (2016) Factors associated with surgical site infection in colorectal surgery: the Japan Nosocomial Infections Surveillance. Infect Control Hosp Epidemiol 35:660-666

Napoli C, Marcotrigiano V, Montagna MT (2012) Air sampling procedures to evaluate microbial contamination: a comparison between active and passive methods in operating theatres. BMC Public Health 12:594

Oren I, Haddad N, Finkelstein R, Rowe JM (2001) Invasive pulmonary aspergillosis in neutropenic patients during hospital construction: before and after chemoprophylaxis and institution of HEPA filters. Am J Haematol 66:257-262

Palladino G, Morozzi P, Biagi E, Brattich E, Turroni S, Rampelli S, Tositti L, Candela M (2021) Particulate matter emission sources and meteorological parameters combine to shape the airborne bacteria communities in the Ligurian coast, Italy. Sci Rep 11:175

Park J, Yoo SY, Ko J-H, Lee SM, Chung YJ, Lee J-H, Peck KR, Min JJ (2020) Infection prevention measures for surgical procedures during a Middle East respiratory syndrome outbreak in a tertiary care hospital in South Korea. Sci Rep 10:1-8

Parvizi J, Barnes S, Shohat N, Edmiston CE Jr (2017) Environment of care: is it time to reassess microbial contamination of the operating room air as a risk factor for surgical site infection in total joint arthroplasty? Am J Infect Control 45:1267-1272

Pasquarella C, Albertini R, Dall'Aglio P, Saccani E, Sansebastiano G, Signorelli C (2008) Air microbial sampling: the state of the art. Igiene e sanita pubblica 64:79-120 
Pasquarella C, Balocco C, Colucci ME, Saccani E, Paroni S, Albertini L, Vitali P, Albertini R (2020) The influence of surgical staff behavior on air quality in a conventionally ventilated operating theatre during a simulated arthroplasty: a case study at the University Hospital of Parma. Int J Environ Res Public Health 17:452

Penel N, Lefebvre J-L, Cazin J, Clisant S, Neu J-C, Dervaux B, Yazdanpanah Y (2008) Additional direct medical costs associated with nosocomial infections after head and neck cancer surgery: a hospital-perspective analysis. Int J Oral Maxillofac Surg 37:135139

Perdelli F, Sartini M, Orlando M, Secchi V, Cristina M (2000) Relationship between settling microbial load and suspended microbial load in operating rooms. Annali di igiene: medicina preventiva e di comunita 12,373

Pinkney TD, Calvert M, Bartlett DC, Gheorghe A, Redman V, Dowswell G, Hawkins W, Mak T, Youssef H, Richardson C (2013) Impact of wound edge protection devices on surgical site infection after laparotomy: multicentre randomised controlled trial (ROSSINI Trial). BMJ 347:f4305

Raisi L, Lazaridis M, Katsivela E (2010) Relationship between airborne microbial and particulate matter concentrations in the ambient air at a Mediterranean site. Global NEST J 12:84-91

Sadeghian P, Wang C, Duwig C, Sadrizadeh S (2020) Impact of surgical lamp design on the risk of surgical site infections in operating rooms with mixing and unidirectional airflow ventilation: a numerical study. J Build Eng 101423

Sadrizadeh S, Holmberg S, Tammelin A (2014) A numerical investigation of vertical and horizontal laminar airflow ventilation in an operating room. Build Environ 82:517-525

Sadrizadeh S, Pantelic J, Sherman M, Clark J, Abouali O (2018) Airborne particle dispersion to an operating room environment during sliding and hinged door opening. J Infect Public Health 11:631-635

Sarıca S, Asan A, Otkun MT, Ture M (2002) Monitoring indoor airborne fungi and bacteria in the different areas of Trakya University Hospital, Edirne, Turkey. Indoor Built Environ 11:285-292

Scaltriti S, Cencetti S, Rovesti S, Marchesi I, Bargellini A, Borella P (2007) Risk factors for particulate and microbial contamination of air in operating theatres. J Hosp Infect 66:320-326

Singh R, Singla P, Chaudhary U (2014) Surgical site infections: classification, risk factors, pathogenesis and preventive management. Int $\mathrm{J}$ Pharm Res Health Sci 2:203-214

Sivagnanasundaram P, Amarasekara R, Madegedara R, Ekanayake A, Magana-Arachchi D (2019) Assessment of airborne bacterial and fungal communities in selected areas of teaching hospital, Kandy, Sri Lanka. BioMed Research International

Smith EB, Raphael IJ, Maltenfort MG, Honsawek S, Dolan K, Younkins EA (2013) The effect of laminar airflow and door openings on operating room contamination. J Arthroplast 28:1482-1485

Sohn AH, Tien NP, Mai VTC, Van Nho V, Hanh TNT, Ewald B, Dibley M (2006) Microbiology of surgical site infections and associated antimicrobial use among Vietnamese orthopaedic and neurosurgical patients. Infect Control Hosp Epidemiol 27:855-862

Spagnolo A, Ottria G, Amicizia D, Perdelli F, Cristina ML (2013) Operating theatre quality and prevention of surgical site infections. J Prev Med Hyg 54:131

Standard IEST (1997) IEST-RP-CC006.2, Testing Cleanrooms. Institute of Environmental Sciences and Technology, USA

Standard ISO (1999) ISO 14644-1, Cleanrooms and associated controlled environments, Classification of air cleanliness. Institute of Environmental Sciences and Technology, United Kingdom

Standard ISO (2003) ISO 14698-1, Cleanrooms and Associated Controlled Environments-Biocontamination Control, Part 1: General Principles and Methods. International Organization for Standardization, United Kingdom
Standard ISO (2005) ISO 14644-3, Cleanrooms and associated controlled environments. Institute of Environmental Sciences and Technology, United Kingdom

Standard MoHM (2010) Policies and procedures on infection control. In: Section QMC (Hrsg.). Ministry of Health Malaysia, Malaysia, pp 1226

Standard NEBB (2009) Procedural standards for certified testing of cleanrooms. Adjusting. and Balancing of Environmental Systems. National Environmental Balancing Bureau, USA

Standard WHO (2012) Environmental monitoring of cleanrooms in vaccine manufacturing facilities, points to consider for manufacturers of human vaccines. World Health Organization (WHO), Geneva, Switzerland, pp 1-37

Tang C-S, Wan G-H (2013) Air quality monitoring of the post-operative recovery room and locations surrounding operating theatres in a medical centre in Taiwan. PLoS ONE 8:e61093-e61093

Tanner J, Khan D, Aplin C, Ball J, Thomas M, Bankart J (2009) Postdischarge surveillance to identify colorectal surgical site infection rates and related costs. J Hosp Infect 72:243-250

Teter J, Guajardo I, Al-Rammah T, Rosson G, Perl TM, Manahan M (2017) Assessment of operating room airflow using air particle counts and direct observation of door openings. Am J Infect Control 45:477-482

Viet Hung N, Anh Thu T, Rosenthal VD, Tat Thanh D, Quoc Anh N, Le Bao TN, Ngo Quang N (2016) Surgical site infection rates in seven cities in Vietnam: findings of the International Nosocomial Infection Control Consortium. Surg Infect 17:243-249

Wagner JA, Schreiber KJ (2014) Improving operating room contamination control. ASHRAE J 56:18

Wagner JA, Greeley DG, Gormley TC, Markel TA (2019) Comparison of operating room air distribution systems using the environmental quality indicator method of dynamic simulated surgical procedures. Am J Infect Control 47:e1-e6

Wan G-H, Chung F-F, Tang C-S (2011) Long-term surveillance of air quality in medical centre operating rooms. Am J Infect Control 39: 302-308

Wang J, Chow T-T (2015) Influence of human movement on the transport of airborne infectious particles in hospital. J Build Perform Simul 8:205-215

Wendlandt R, Thomas M, Kienast B, Schulz AP (2016) In-vitro evaluation of surgical helmet systems for protecting surgeons from droplets generated during orthopaedic procedures. J Hosp Infect 94:75-79

Wong KY (2019) Medical staff's movement effects on particle counts in a surgical zone. Universiti Teknologi Malaysia, School of Graduate Studies, $226 \mathrm{pp}$

Wong KA, Holloway S (n.d.) An observational study of the surgical site infection rate in a General Surgery Department at a General Hospital in Malaysia

Wong KY, Kamar HM, Kamsah N, Zawawi FM, Deris MS (2017) Effect of air change rate on airborne particles concentration in hospital operating rooms. Int J Adv Res Eng Technol 1:1-6

Wong KY, Kamar HM, Kamsah N, Zawawi FM, Tan H, Musa MN, Deris MS (2018) Correlation between particulate matter and microbial counts in hospital operating rooms. Adv Environ Biol 10:1-4

Young SW, Zhu M, Shirley OC, Wu Q, Spangehl MJ (2016) Do 'surgical helmet systems' or 'body exhaust suits' affect contamination and deep infection rates in arthroplasty? A systematic review. J Arthroplast 31:225-233

Zhou B, Ding L, Li F, Xue K, Nielsen PV, Xu Y (2018) Influence of opening and closing process of sliding door on interface airflow characteristic in the operating room. Build Environ 144:459-473

Publisher's note Springer Nature remains neutral with regard to jurisdictional claims in published maps and institutional affiliations. 